\title{
Homicídios Juvenis e os Desafios à Democracia Brasileira: Implicações Ético-políticas da Psicologia
}

\author{
João Paulo Pereira Barros \\ Universidade Federal do Ceará, CE, Brasil. \\ Dagualberto Barboza da Silva \\ Universidade Federal do Ceará, CE, Brasil.
}

Luis Fernando de Souza Benicio

Universidade Federal do Ceará, CE, Brasil.

Camila dos Santos Leonardo

Universidade Federal do Ceará, CE, Brasil.

Frida Jaina Popp Torres

Universidade Federal do Ceará, CE, Brasil.

Resumo:Ocrescentehomicídio de jovensérealidade preocupante nocenário sociopolítico brasileiro. A elevação dos índices, desde o final da década de 1970 até os dias atuais, aponta para a continuidade de maquinarias autoritárias e para a fragilidade de processos de consolidação democrática no país. O objetivo deste artigo é problematizar os homicídios juvenis como analisadores dos desafios à democracia brasileira e das implicações ético-políticas da Psicologia nas lutas por democratização. Tal discussão se estabelecerá a partir de interlocuções da Psicologia Social com estudos de Foucault, Deleuze, Guattari e Agamben. Em um primeiro momento do texto, será discutido como a questão dos homicídios de jovens se relaciona com a intensificação de modos fascistas de viver no interior das formações ditas "democráticas". Posteriormente, a repercussão social e midiática da chacina considerada como a maior da história do Ceará será tomada como um acontecimento-analisador da operação de dispositivos de criminalização juvenis e de produção de "sujeitos matáveis" no cotidiano de nossos grandes centros urbanos, entendendo que o panorama da violência na cidade de Fortaleza é um caleidoscópio do que vem ocorrendo no cenário nacional. Por fim, o artigo aponta possibilidades acerca da implicação ético-política da Psicologia na luta por democratização, por meio da apresentação de caminhos de pesquisa e extensão desenvolvidos pelo Grupo de Pesquisas e Intervenções sobre Violências e Produção de Subjetividades (Vieses-UFC).

Palavras-chave: Homicídios, Jovens, Democracia, Psicologia. 


\title{
Juvenile Homicides and the Challenges to Brazilian Democracy: Ethical-political Implications of Psychology
}

\begin{abstract}
The increasing homicide of young people is a worrying reality in the Brazilian sociopolitical scenario. The elevation of the indexes, from the end of the 1970s to the present day, points to the continuity of authoritarian machinery and the fragility of its processes of democratic consolidation. The objective of this article is to problematize juvenile homicides as analyzers of the challenges to Brazilian democracy and the ethical-political implications of Psychology in the struggles for democratization. Such a discussion will be established from Social Psychology interlocutions with studies by Foucault, Deleuze, Guattari and Agamben. In the first part of the text, it will be discussed how the issue of youth homicide is related to the intensification of fascist ways of living within the so-called "democratic" formations. Subsequently, the social and media repercussion of the slaughter considered as the largest in the history of Ceará will be taken as an analyzing event of how juvenile criminalization devices and the production of "killable subjects" operate in the daily life of our great urban centers, understanding that the panorama of violence in the city of Fortaleza is a kaleidoscope of what has been happening in the national scenario. Finally, the article points out possibilities about the ethical-political implication of Psychology in the struggle for democratization, through the presentation of research and extension paths developed by the Research and Intervention Group on Violence and Production of Subjectivities (Vieses-UFC).
\end{abstract}

Keywords: Homicide, Young, Democracy, Psychology.

\section{Homicidios Juveniles y los Desafíos a la Democracia Brasileña: Implicaciones Ético-Políticas de la Psicología}

Resumen: El creciente homicidio de jóvenes es realidad preocupante en el escenario sociopolítico brasileño. El aumento de los índices, desde el final de la década de 1970 hasta los días actuales, apunta a la continuidad de maquinarias autoritarias y a la fragilidad de sus procesos de consolidación democrática. El objetivo de este artículo es problematizar los homicidios juveniles como analizadores de los desafíos a la democracia brasileña y de las implicaciones ético-políticas de la Psicología en las luchas por democratización. Tal discusión se establecerá a partir de interlocuciones de la Psicología Social con estudios de Foucault, Deleuze, Guattari y Agamben. En un primer momento del texto, será discutido cómo a cuestión de los homicidios de jóvenes se relaciona con la intensificación de modos fascistas de vivir al interior de formaciones consideradas "democráticas". Posteriormente, la repercusión social y mediática de la considerada como la mayor masacre de la historia de Ceará será tomada como un acontecimiento-analizador de la operación de dispositivos de criminalización juveniles y de producción de "sujetos matables" en el cotidiano de nuestros grandes centros urbanos, entendiendo que el panorama de la violencia en la ciudad de Fortaleza es un caleidoscopio de lo que viene ocurriendo en el escenario nacional. Finalmente, el artículo apunta posibilidades sobre la implicación ético-política de la Psicología en la lucha por democratización, por medio de la presentación de caminos de investigación y extensión desarrollados por el Grupo de Investigaciones e Intervenciones sobre Violencias y Producción de Subjetividades (Vieses-UFC).

Palabras claves: Homicidios, Jóvenes, Democracia, Psicología. 


\section{Introdução: o cenário sociopolítico brasileiro e a atualidade de maquinarias autoritárias}

Nos últimos anos, tem havido um progressivo acréscimo das taxas de homicídios no Brasil, de acordo com levantamento de Waiselfisz (2016). De janeiro de 2011 a dezembro de 2015, foram mortas mais pessoas no nosso país do que na Guerra da Síria (Fórum Brasileiro de Segurança Pública, 2016).

Em 2015, ocorreram 59.080 homicídios ou, em outra leitura, atingimos uma taxa de 28,9 mortes por 100 mil habitantes. Vale destacar que $47,8 \%$ do número total se refere à mortalidade da juventude masculina que possuía entre 15 a 29 anos. Ao considerar, por exemplo, a juventude masculina de 15 a 19 anos dentro do dado anterior, percebe-se que esse segmento representa $53,8 \%$ da amostra (Cerqueira et al., 2017). No ano anterior, 2014, foram contabilizados 59.627 homicídios, o que representa mais de $10 \%$ dos homicídios registrados no mundo, colocando-nos como o país com o maior número absoluto desse tipo de violência letal (Cerqueira et al., 2016). A partir desse mesmo levantamento, constata-se que $53 \%$ dos homicídios são referentes à população jovem, correspondente à faixa etária de 15-19 anos, atingindo, predominantemente, o sexo masculino.

Entre 1980 e 2013, foram assassinados 207.438 crianças e adolescentes, aqui, as taxas de homicídios para esse segmento quintuplicaram. Só em 2013, foram mais de 10 mil assassinatos, representando a terceira maior taxa de homicídios de crianças e adolescentes em uma lista com 85 países (16,3/100 mil) (Waiselfisz, 2015).

Além disso, realizando um recorte racial, Cerqueira et al. (2017) apontam que, entre 2005 e 2015, 71 de cada 100 pessoas que sofreram homicídio no Brasil eram negras. A taxa de homicídio de negros cresceu $18,2 \%$, ao passo que ocorreu uma diminuição de $12,2 \%$ na vitimização de indivíduos de outras raças e, assim, em 2015, foram mortos 2,4 negros para cada não negro. Para Cerqueira e Coelho (2015), o risco de ser vítima de homicídio é maior para os jovens entre 15 e 29 anos. Dessa forma, para os autores, ser negro e possuir 21 anos de idade aumenta a probabilidade em $147 \%$ de serem vitimizados. Estudos como o de Paiva e Freitas (2015) e Barros, Acioly e Ribeiro (2016), ao pensarem o perfil da juventude que aparece nos indicadores, denunciam que as juventudes negras, pobres $\mathrm{e}$ que residem nas periferias urbanas são o principal alvo desse tipo de violência, seja por conta de conflitos com a polícia, seja pela ação de grupos de extermínios e/ou, ainda, por conflitos territoriais decorrentes da disputa entre facções ligadas ao tráfico de drogas e armas.

Segundo Mingardi (2015, p. 16), "um dos insumos da violência é mesmo a ausência de democracia real”. A elevação dos índices de homicídios no Brasil, desde o final da década de 1970 aos dias atuais, aponta a continuidade de maquinarias autoritárias e a fragilidade de seus processos de consolidação democrática, como apontam Barreira e Batista (2011) e Santos (2011). Nesse sentido, Batista (2015, p. 240) sustenta que "a ideologia do extermínio é hoje muito mais massiva e introjetada do que nos anos imediatamente posteriores ao fim da ditadura". Já estudos como o de Fraga (2004) frisam que a intensificação da violência criminal e institucional coincide com o fim da ditadura civil-militar e que jovens negros e pobres encontram-se cada vez mais no fogo cruzado de um autoritarismo social, que diz respeito à perpetuação no tecido social e nas suas instituições de relação hierárquica e adoção da violência como forma de resolução das tensões e conflitos sociais.

O objetivo deste artigo é problematizar o recrudescimento de homicídios de jovens como analisador dos desafios à democracia brasileira e das implicações ético-políticas da Psicologia nas lutas por democratização. Tal discussão se estabelecerá a partir de interlocuções da Psicologia Social com estudos de Foucault, Deleuze e Guattari sobre modos fascistas de viver e com as reflexões de Agamben sobre "estado de exceção", considerando que os legados desses autores são importantes caixas de ferramentas teóricas para a problematização da proliferação da apologia à violência letal e sua institucionalização em solo brasileiro, bem como para potencializar discussões sobre o que pode a Psicologia como ciência e profissão nesse contexto.

No próximo tópico, discutiremos como a questão dos homicídios de jovens se relaciona com a intensificação de modos fascistas de viver no interior das formações ditas "democráticas". Posteriormente, tomaremos as repercussões midiáticas da chacina ocorrida no dia 12 de novembro de 2015, em territórios periféricos de Fortaleza, considerada a maior da história do Ceará, como acontecimento-analisador de como operam dispositivos de criminalização juvenis e de produção de "sujeitos matáveis" no cotidiano de nossos grandes centros urbanos. Por fim, no intuito de apontar possibilidades concernentes à implicação ético-política da Psicologia na luta por democratização, 
apresentaremos caminhos de pesquisa e extensão desenvolvidos na cidade de Fortaleza pelo Grupo de Pesquisas e Intervenções sobre Violências e Produção de Subjetividades (Vieses), ligado ao Departamento de Psicologia e ao Programa de Pós-graduação em Psicologia da Universidade Federal do Ceará (UFC).

A escolha por abordar aspectos do contexto de Fortaleza nos últimos tópicos deste artigo se deve ao fato de que seu panorama constitui um caleidoscópio do que vem ocorrendo no cenário nacional, tal como reconhecem representantes do Fundo das Nações Unidas para a Infância (Unicef). De acordo com o Atlas da Violência 2017, Fortaleza é a capital do país que apresenta o maior número de homicídios (Cerqueira et al., 2017). No caso dos segmentos juvenis, a realidade é ainda mais preocupante na capital do Ceará, que, em 2014, apresentou, pela segunda vez, o maior índice de homicídios na adolescência (IHA) entre as capitais brasileiras, com o valor de 10,94/mil, ou seja, se mudanças significativas não forem realizadas, cerca de $11 \mathrm{em}$ cada mil adolescentes serão vítimas de homicídio antes de chegar aos 19 anos (Melo, \& Cano, 2017). Isso representou um crescimento de $365 \%$ em relação ao seu IHA de 2015. Esses dados apontam um processo de "nordestinação" da violência letal no Brasil, já que oito dos dez estados com mais elevados IHA são dessa região, sendo o Ceará o que apresentou o mais alto índice.

Na capital cearense, os homicídios de pessoas de 10 a 19 anos vem atingindo níveis mais elevados que os da população em geral a partir de 2006, de acordo com a Célula de Vigilância Epidemiológica da Secretaria Municipal de Saúde de Fortaleza, que tem realizado análises epidemiológicas e espaciais sobre a dinâmica da violência letal. Esse levantamento também realça que, a partir de 2013, as causas externas, em especial os homicídios, passaram a ser a maior causa de morte na cidade. Além disso, chama atenção para o fato de que a maior parte das vítimas dos assassinatos, em 2015, pertenciam à faixa etária de 15-19 anos e foram vitimadas por disparo de arma de fogo (Fortaleza, 2016).

\section{Homicídio de juventudes no Brasil e suas relações com modos fascistas de viver: desafios à "democracia” brasileira}

As intercessões com Foucault, Deleuze e Guattari permitem entrever que formas fascistas de vida podem se produzir no interior das próprias formações ditas "democráticas". Foucault (1994) declarou o seguinte sobre tais formações:
Se se entende por democracia o exercício efetivo de um poder por uma população que não está dividida nem ordenada hierarquicamente em classes, é perfeitamente claro que estamos muito longe dela. É também claro que vivemos um regime de ditadura de classe, poder de classe que se impõe pela violência, ainda que os instrumentos dessa violência sejam institucionais e constitucionais (p. 497).

Tomando essas discussões como "caixas de ferramenta", frisamos que as diversas modalidades de fascismo, das mais vultosas às "formas pequenas que fazem a amena tirania de nossas vidas cotidianas" (Foucault, 1994, p. 136), implicam a deslegitimação de uma série de existências, as quais variam conforme o contexto histórico-social, passando a ser aniquiladas ou mantidas numa margem de exclusão em nome da "ordem". As práticas autoritárias e as distintas formas de violência perpetradas pelo Estado são agenciadas justamente por essa repulsa a certas existências que caracteriza modos fascistas de viver. Articuladamente à tradição escravocrata e elitista, tem-se aí uma possível chave analítica frente à aparente naturalização com que parcela significativa da sociedade brasileira admite e até demanda o extermínio de certas juventudes no Brasil associadas à pobreza, ao risco e à criminalidade, em pleno "regime democrático".

Em meio às suas discussões sobre biopolítica e governamentalidade, em meados da década de 1970, Foucault chama atenção para o fato de que o nazifascismo de Hitler e Mussolini soube utilizar, habilmente, o desejo das massas e não teria se implantado sem que uma "porção relativamente importante da população se encarregasse das funções de repressão, de controle e de polícia" (Foucault, 1994, p. 654).

Nessa mesma direção, as discussões esquizoanalíticas de Deleuze e Guattari (1991) realçam que "as massas não foram enganadas, elas desejaram o fascismo num certo momento, em determinadas circunstâncias" (p. 47). Lembram-nos que aquele regime totalitário se caracterizou por ser uma das formas mais eficientes de gestão de coletividades em espaços abertos, devido à sua capacidade de articular, molecularmente, multiplicidades então dispersas. Por sua vez, em Revolução molecular: pulsações políticas do desejo, Guattari (1987) propõe uma análise micropolítica do fascismo, permitindo-nos elucidar a atualização de suas maquinarias na contemporaneidade. $\mathrm{O}$ 
fascismo, sustenta o autor, radica-se em práticas cotidianas, e não somente por meio de um Estado totalitário. Sua abordagem analítico-política do fascismo põe em xeque, portanto, a produção de subjetividades serializadas ensejada pelo fascismo:

Desenvolvem-se novas formas de fascismo molecular [...] por toda a parte, a máquina totalitária experimenta estrutura que melhor se adaptem à situação: isto é, mais adequadas para captar o desejo e colocá-lo a serviço da economia de lucro. Dever-se-ia, portanto, renunciar definitivamente a fórmulas demasiado simplistas do gênero: "o fascismo não passará". Ele não só já passou como passa sem parar. Passa através da mais fina malha; ele está em constante evolução: parece vir de fora, mas encontra sua energia no coração do desejo de cada um de nós. Em situações aparentemente sem problemas, catástrofes podem aparecer de um dia para o outro. O fascismo, assim como o desejo está espalhado por toda parte, em peças descartáveis, no conjunto do campo social; ele toma forma, num lugar ou noutro, em função das relações de forças. Pode-se dizer dele, ao mesmo tempo, que é superpotente de uma fraqueza irrisória (p.188-189).

No prefácio de $\mathrm{O}$ anti-Édipo, em texto intitulado "Anti-Édipo: uma introdução à vida não fascista", Foucault (1993) assim questiona: como nos desvencilhar do fascismo que atravessa nossos discursos e nossas ações cotidianas? Essa provocação expressa uma das principais características da trajetória de Foucault: a ênfase nos processos de cunho microfísico, porém com maiúsculos efeitos, ao invés da primazia dos grandes sistemas de poder.

A inserção no campo teórico que articula esses pensadores da diferença nos possibilita considerar a coextensão do campo social e da produção do desejo na análise das expressões fascistas que se alastram no cenário político do Brasil, particularmente ao tema da violência envolvendo jovens. Problematizar o recrudescimento dos homicídios de jovens negros e pobres como expressão de uma uma espécie de "fascismo à brasileira" implica, por seu turno, perscrutar que modos de subjetivação estão sendo engendrados em nome da "segurança" e da "justiça".

Ao pautarem a subjetivação capitalística, Deleuze e Guattari (1991) apresentam que a axiomá- tica do capital em nossos tempos envolve a descodificação de antigos fluxos sociais e a produção de um novo diagrama de forças, visando à modulação desses fluxos na lógica do aprimoramento do controle social. A esse respeito, podemos destacar a crescente modulação dos investimentos desejantes das massas em nome da segurança no Brasil, fenômeno fortemente conectado à espetacularização e mercantilização da violência. Fazem parte da paisagem cotidiana a pregnância de discursos de ódio e práticas de intolerância contra quem escapa à norma. Esses aspectos mostram, tal como discutem os esquizoanalistas, que o fascismo não opera somente verticalmente, mas também lateralmente e por ressonância. Um exemplo disso é que, de acordo com o 9 Anuário Brasileiro de Segurança Pública, mais da metade da população corrobora com a sentença "bandido bom é bandido morto", constatação que se torna ainda mais preocupante em um país cuja polícia militar é uma das mais letais do mundo (Fórum Brasileiro de Segurança Pública, 2015).

O contexto de crise político-econômico-social, como também observado em outros momentos históricos, tem aberto um amplo espaço ao espraiamento de posições conservadoras frente a diversos temas concernentes à violência. Ilustrativamente, podemos citar aquelas a favor de "menos escolas e mais prisões”; da redução da idade penal; da castração química de estupradores; da internação compulsória de pobres usuários de drogas ilícitas, da pena de morte, bem como da militarização de instituições de segurança pública e dos modos de viver na cidade.

Dois pontos merecem realce nesse cenário conversador observado no Brasil, o qual enseja uma espécie de "engajamento subjetivo aos (micro)fascismos": primeiro, essas codificações maciças decorrentes dos investimentos desejantes em paranoias securitárias parecem ser uma resposta às desterritorializações capitalísticas atuais, ainda que findem reafirmando subjetivações serializantes típicas do próprio capitalismo; segundo, a disposição a (micro)fascismos conecta-se à instrumentalização política do medo no contexto da governamentalidade neoliberal e à produção de sujeições pela via da criminalização, corroborando com a construção de inimigos nos quais a população deposita seus desassossegos e a quem destina a eliminação simbólica e, em muitos casos, física também, como faz ver a elevação do número de homicídios em nosso país. 
Uma das mais contundentes ilustrações da molecularidade do fascismo e de sua capacidade de modulação dos investimentos desejantes das massas em nome da "justiça" é o fenômeno dos linchamentos no Brasil. Somos o país onde mais são praticados "justiçamentos”: é o que aponta Martins (2015), em seu livro Linchamentos: a justiça popular no Brasil. Ainda segundo o autor, esses casos vêm aumentando desde 2013.

Entendemos que, embora sejam a manifestação de uma sanha coletiva, os linchamentos não se tratam propriamente de fenômenos espontâneos. Ancoram-se em certos repertórios de crenças e em determinadas formações discursivas, relacionadas à descrença no Estado e no sistema de justiça, bem como à desqualificação dos direitos humanos e do Estado Democrático de Direito. Tampouco os alvos de linchamento são aleatórios: em um contexto de desigualdades sociais e raciais, são os mesmos que mais morrem por homicídio e a quem se direcionam a violência policial e as medidas de encarceramento em massa.

Além da atuação e,ou omissão do Estado na perpetuação de um ethos da eliminação de "vidas infames", os dispositivos midiáticos têm um papel importante na produção de condições para os linchamentos e para a própria escalada de homicídios. Isso porque uma gama de programas policialescos em profusão nas TVs brasileiras consolida no imaginário social as conexões entre juventude negra, pobreza, delinquência e impunidade, ao passo que desqualificam sistematicamente as temáticas e militâncias concernentes aos direitos humanos.

Como se produz a banalização das mortes de juventudes pobres, negras e inseridas nas margens urbanas, em uma sociedade que reivindica a todo momento a preservação da vida? Em períodos de espetacularização/mercantilização da violência e de uso do medo como operador político, ganha robustez a sensação de que é preciso solapar as leis para se fazer justiça. Na mesma velocidade com que histórias de violência viram entretenimento midiático, amplia-se a aceitabilidade em relação às mortes de uma parcela significativa de pessoas, desumanizando-as, em defesa de algumas vidas.

$\mathrm{O}$ panorama ora exposto, em que a violência urbana nos divide e maximiza nossas desigualdades sociais, remete às relações discutidas por Foucault (2005) entre a biopolítica e o "racismo de Estado", nas aulas de 1976 contidas no livro Em defesa da sociedade. Sob essa ótica, o racismo é um meio de inserir, no seio da tecnologia de poder que objetiva a maximização da vida, um corte que estabelece os que devem viver e os que devem morrer, hierarquizando, portanto, o corpo da população.

O racismo do qual fala o pensador francês é "a condição de aceitabilidade de tirar a vida numa sociedade da normalização" (Foucault, 2005, p. 214). Além de fragmentar a população em grupos, o racismo de Estado possibilita que os autointitulados "cidadãos de bem" reclamem a morte e exponham à morte os indivíduos que lhes parecem a objetificação do mal.

Vocês compreendem, em consequência, a importância - eu ia dizer a importância vital - do racismo no exercício de um poder assim: é a condição para que se possa exercer o direito de matar. Se o poder de normalização quer exercer o velho direito soberano de matar, ele tem que passar pelo racismo. $\mathrm{E}$ se, inversamente, um poder de soberania, ou seja, um poder que tem direito de vida e de morte, quer funcionar com os instrumentos, com os mecanismos, com as tecnologias de normalização, ele tem que passar pelo racismo. É claro, por tirar a vida, não entendo simplesmente o assassínio direto, mas também tudo o que pode ser assassínio indireto: o fato de expor à morte, de multiplicar para alguns o risco de morte ou, pura e simplesmente a morte política, a expulsão, a rejeição, etc. (Foucault, 2005, p. 215).

No Brasil, a questão do racismo é ainda mais complexa. Podemos entender que a intensificação dos homicídios de jovens em sua grande maioria negros, pobres e habitantes das margens urbanas, considerados como aqueles que devem morrer em defesa da sociedade, em nome da ordem, trata-se de uma problemática colonial.

Para exemplificar como essa questão opera no Brasil, trazemos um fato que se destacou nos noticiários brasileiros e internacionais em janeiro de 2017: a chacina de dezenas de detentos dentro de presídios na Região Norte do país, atribuída ao acirramento do embate entre facções pelo mercado ilícito de drogas e armas. "Ali não tinha nenhum santo", assim comentou publicamente o governador do Estado do Amazonas, referindo-se ao massacre em uma penitenciária de Manaus. "Tinha de ter uma chacina por semana”, declarou o Secretário Nacional de Juventude, sobre o mesmo fato, a uma coluna publicada 
no dia 6 de janeiro de 2017, no site do Jornal O Globo (Franco, 2017).

Os posicionamentos desses agentes públicos sugerem não haver motivos para que a população em geral e o Estado se importem com aquelas mortes, presumindo a indignidade daquelas vidas. $\mathrm{O}$ perfil da população de encarcerados no Brasil se assemelha ao das maiores vítimas de homicídio no país. Segundo dados do Sistema Integrado de Informação Penitenciária - Infopen, do Governo Federal, o país saltou de aproximadamente 233 mil presos no ano de 2000 para cerca de 622 mil em 2014. Os presos são, em sua maior parte, jovens (56\%), negros (67\%), moradores de periferias urbanas e com baixa escolaridade.

Assim, problematizando a gestão da pobreza no Brasil, as mortes de juventudes indesejáveis não se dão apenas por seu extermínio propriamente dito, mas também por meio de suas invisibilizações sociais, pelas visibilidades estigmatizantes, pelos estados de morte em vida decorrentes da precariedade das políticas sociais, pelas situações de reclusão, de inclusão perversa e de exposição à morte em seus locais de moradia emblematizada pela rotinização dos confrontos entre sujeitos pobres supostamente envolvidos no tráfico de drogas ilícitas e policiais nas favelas.

Nesse sentido, uma das principais expressões da intensificação de modos fascistas de vida em solo brasileiro e da naturalização da violência daí resultante é a política de "guerra às drogas". Batista (1997) pontua que a política de drogas brasileira, a exemplo da estadunidense, é uma "política criminal com derramamento de sangue" (p. 129). A biopolítica de "guerra às drogas" vem assumindo uma função estratégica de efetivar determinados modos de fazer viver e fazer morrer. Trata-se, pois, de uma das responsáveis pela política de extermínio crônica e institucionalizada de "sujeitos matáveis". Reiterando sua marca colonial, a "guerra às drogas" tem sido efetivamente um dispositivo moral, religioso, político e racial voltado ao massacre de jovens negros e pobres das periferias urbanas, transformados em "inimigos internos", como aponta Batista (2003), ao estudar sobre drogas e juventudes pobres no Rio de Janeiro.

Souza (2014) apresenta que "a partir das drogas, e suas subdivisões, é possível categorizar os indivíduos e repartir o conjunto da população entre saudáveis e doentes e entre criminosos e não criminosos" (p. 990). Reiterando as reflexões desse autor, Barros, Acioly e Ribeiro (2016), ao tematizarem o contexto do Ceará e de Fortaleza, refletem como o proibicionismo e o modelo de "guerra às drogas" maximizam o espectro das intervenções que operam esquadrinhamentos, subdivisões, hierarquizações e normalizações sobre a vida do conjunto da população. Produz-se, nessa trama, o apelo social da criminalização do uso de determinadas drogas, bem como se atualizam associações do signo da droga à pobreza e estigmatizações de territórios periféricos como perigosos, o que cria condições para o aumento dos assassinatos de segmentos juvenis, a quem comumente se atribui a pecha de "envolvidos".

A partir dessas conexões entre políticas sobre drogas, violência urbana e suas implicações para as juventudes negras, pobres e inseridas nas margens urbanas, a trivialização do extermínio dessas juventudes está implicada à produção do que Coimbra e Scheinvar (2012) chamam de "subjetividades punitivo-penais", referindo-se à consolidação nos nossos modos de existência dos parâmetros punitivos como instrumentos privilegiados para superação dos conflitos sociais cotidianos e sofrimentos daí resultantes. Portanto, o que vemos crescer hoje no Brasil e aqui chamamos de "engajamento subjetivo aos fascismos", inspirados na noção de "adesão subjetiva à barbárie” (Batista, 2012), está imbricado à maximização/internalização de uma maquinaria punitivista e penalizante que exacerba iniquidades históricas e ao desejo de práticas autoritárias que aniquilem existências socialmente desqualificadas, ao borrar os limiares entre justiça e vingança à proporção que realça as fronteiras entre quem deve viver ("cidadão") e quem deve morrer (“criminoso").

\section{Criminalização de juventudes e a produção de "sujeitos matáveis": a "Chacina de Messejana" como acontecimento-analisador}

Na madrugada do dia 11 para o dia 12 de novembro de 2015, em territórios localizados na Grande Messejana, na periferia de Fortaleza, 11 pessoas foram assassinadas e sete ficaram feridas, no episódio que, a partir de sua repercussão midiática, ficou conhecido como a maior chacina do estado do Ceará. Todas as vítimas eram do sexo masculino, nove deles jovens entre 16 e 19 anos de idade - assassinados em um intervalo de apenas 4 horas. Nove meses depois da chacina, em agosto de 2016, as investigações culminariam na prisão preventiva de 44 policiais militares 
acusados de envolvimento na "Chacina da Messejana”, como ficou mais popularmente conhecido o caso na capital e em outras regiões do estado.

Nos dias seguintes, diversos veículos de comunicação repercutiam as 11 mortes na Grande Messejana. Tomaremos, portanto, esta chacina e suas repercussões midiáticas como analisadoras da produção social de sujeitos "indignos de vida" ((Zaccone, 2015) a partir de processos de criminalização de juventudes negras e pobres. Para tal, colocamos em análise notícias publicadas dias após a chacina nos portais online do estado do Ceará e os comentários produzidos pelos leitores de tais notícias.

A princípio, destacamos um comentário feito por uma leitora sobre a matéria "Nenhuma das vítimas da chacina da Messejana tinha antecedentes criminais graves", do Tribuna do Ceará, publicada no dia 12 de novembro de 2015 (Narlla, 2015). A notícia trazia que os assassinados não tinham antecedentes criminais graves, permitindo-nos uma problematização sobre o que se tornou habitual: investigar primeiramente a ficha criminal daqueles que têm suas vidas ceifadas para só então averiguar se sua morte é ou não caracterizada como violência e passível de luto, em uma tentativa de buscar nas vítimas (e não nos diversos e complexos fatores que compõem a violência) as razões para seu extermínio. No contexto de Fortaleza, a capital brasileira onde mais se tem homicídios de adolescentes e jovens, essa lógica tem permitido que as mortes de alguns segmentos da sociedade sejam legitimadas e, por vezes, até mesmo estimuladas.

Não tenho medo da polícia, até porque sou uma cidadã de bem e quem não deve, não teme. [...] nenhum tinha antecedentes graves... hãm? O cara com 17 anos, já responde por crime de trânsito? Já era habilitado, então? O outro com 18, por pensão, que sim, dá cadeia, o outro respondia por ameaça, art. 147 do cód. penal. Isso não é grave, né? Por enquanto, é o que sabemos e 3 respondiam por crimes sim... Não crimes hediondos, mas dizer que não tinham antecedentes criminais, é hipocrisia. $\mathrm{O}$ fato dos demais não terem passagem não faz deles santos. $\mathrm{O}$ que faziam de madrugada na rua? Estavam trabalhando? SSPC e MP apurem os fatos, porque aí tem. Direitos humanos? Uhum sei... Defensores do que não presta, isso sim. Pra eles o que interessa, é defender a bandidagem e oprimir o cidadão.
Logo após a chacina, na manhã do dia 12 de novembro, foi publicada no O Povo Online (2015a) a matéria "SSPDS monta força-tarefa para investigar chacinas e homicídios”. Nesta havia a indicação de três linhas de investigação que haviam sido instauradas - uma apontava que as mortes teriam sido retaliações pela prisão de Castor, ligado ao tráfico de drogas na região; outra considerava uma vingança pela morte de uma pessoa também vinculada, supostamente, ao tráfico de drogas. A terceira linha apontava o envolvimento dos policiais e foi descredibilizada ao longo da cobertura do caso, de maneira que, embora meses após a chacina, quando esta linha investigativa já prevalecia sobre as outras hipóteses, ainda podíamos perceber o episódio sendo abordado como consequência de uma disputa interna do "crime" na Grande Messejana. Na mesma matéria (2015), encontramos o seguinte comentário feito por um internauta: "Com milhares de crimes contra cidadãos do bem, pessoas honradas, pais de família e a polícia vai investigar assassinatos de traficantes, drogados, latrocidas, homicida e o pior, justamente aqueles que os caçam feitos ratos. Vergonha!”. Admitia-se, assim, que a morte de "envolvidos" era um fenômeno a ser naturalizado e passível de adesão. "Bandidos" figuravam, em tal contexto enunciativo, como "não cidadãos", logo eram "matáveis" (Paiva, 2015; Barros, Acioly \& Ribeiro, 2016).

A repercussão social e midiática da Chacina da Messejana escancarou o processo que Batista (2012) chamou de "adesão subjetiva à barbárie", que se refere à crescente demanda coletiva por mais punição e castigo, e à cruel divisão feita, em tempos neoliberais, de sujeitos que têm direito à vida e aqueles cuja morte é autorizada e desejada. Como é possível observar a partir da repercussão da chacina em análise, a existência de antecedentes criminais ou o possível envolvimento com o tráfico funcionam, no dia a dia de territórios da periferia dos centros urbanos e nas (entre)linhas dos noticiários policiais, como justificativa para as mortes cuja autoria se atribui a representantes do Estado.

Depois da divulgação oficial de que as vítimas eram "inocentes", não sendo, portanto, enquadráveis no estereótipo de "envolvidos", cresceu a repercussão daquela chacina, diferente do que tem acontecido em relação a outros episódios de extermínio que ocorrem cotidianamente nas periferias de Fortaleza e do Ceará. No entanto, mesmo depois de a Secretaria de Segu- 
rança Pública estadual comunicar que as vítimas não tinham antecedentes criminais e começar a circular a informação de que policiais civis e militares eram suspeitos do crime, não cessou a proliferação de discursos de suspeição em relação aos assassinados nas notícias e seus comentários, já que não se tinha como atitude de "cidadão de bem" estar na rua em horário considerado inapropriado. Eis o fio desses diversos discursos de suspeição: se eles estavam na rua, considerada como um espaço de perigo iminente (Coimbra, 2001), àquela hora da noite, ou eles estavam envolvidos em alguma prática "delituosa" ou, se não, assumiram o risco de serem vítimas de violência, sendo também responsáveis pelo seu próprio assassinato. Essa foi uma das formas pela qual se questionou a dignidade das vidas dos 11 mortos na Chacina da Messejana.

Assim, as mortes se tornaram admissíveis socialmente, sendo suas vidas configuradas, destarte, como "vidas nuas" (Agamben, 2009). A Chacina da Messejana nos possibilita pôr em debate algumas características da intensificação de estados de exceção permanente na democracia atual (Agamben, 2004), bem como a reverberação desses regimes no cotidiano de juventudes que habitam as margens urbanas. Afinal, embora não esteja prevista no Código Penal brasileiro a pena de morte, os vultosos números de homicídios de jovens e a aceitação social desse quadro mostram que a pena de morte, em se tratando de jovens negros e pobres, não é algo excepcional nas periferias das grandes cidades. Isso nos impõe o desafio de pensar para quais humanos os "direitos humanos" têm de fato se destinado historicamente. Em vista disso, ao invés de falar de "direitos humanos" genericamente, é fundamental pôr em questão de que humanos ou de que direitos (e de que concepção de cidadania) se está falando (Bicalho, Barbosa \& Meza, 2015; Barros, Acioly \& Ribeiro, 2016; Coimbra, Lobo \& Nascimento, 2008)

Com base na repercussão midiática da Chacina de Messejana, as vidas de suas vítimas foram consideradas, num primeiro momento, como desimportantes. Da intensificação dos regimes de exceção, é crucial observar que a isso estão ligadas práticas de assujeitamento típicas da produção de subjetividades capitalísticas. Guattari e Rolnik (2007) discorrem sobre três formas de assujeitamento: segregação, culpabilização e o que podemos chamar de silenciamento. Lendo esses três modos de assujeitar o outro, o indesejável, o considerado "improdutivo", "vagabundo", chegamos às práticas discursivas que perpassaram e buscaram legitimar a morte dos 11 chacinados, afora os casos que não nos chegam por não se terem efetivado no assassínio de pessoas que pudessem "comover" para além da própria família. Foucault (2005) nos fala que não podemos compreender a produção da morte de "indesejáveis" apenas pelo homicídio, mas também por processos simbólicos e políticos de exposição à morte e inviabilização da vida.

Dessa maneira, a segregação e a impossibilidade de exercer a vida política estariam cumprindo a função de racismo de Estado (Foucault, 2005). A culpabilização das vítimas foi um elemento que se fez bastante presente nos discursos sobre a Chacina, seja na voz de representantes da segurança pública, seja nos dispositivos midiáticos hegemônicos na capital do Ceará.

A Chacina em questão e a sua repercussão mostram que as noções de segurança, risco e periculosidade, associadas à condição de jovens negros e pobres, são racionalidades operantes que têm permitido a perpetuação de estados de exceção em nossa democracia atual. O discurso do risco produz sobre certos sujeitos a imagem do inimigo social, sobre os quais a violação de direitos e a violência de Estado passam a ser legitimada. Coimbra e Nascimento (2003, p. 19) discutem sobre os efeitos forjados "pelas práticas que têm associado periculosidade, criminalidade e a condição de não-humanidade à situação de pobreza", compreendendo que tais associações têm sido expressas significativamente pelos extermínios de jovens negros, pobres e moradores de periferia.

Com base nisso, tornam-se preocupantes discursos como: "deveriam ser 100, pelo menos há uma menor quantidade de bandidos nas ruas, ou seja, quantos mais bandidos mortos... melhor para a sociedade", comentário de leitor sobre matéria "Secretaria divulga lista dos 11 mortos em chacinas na Grande Messejana", publicação feita do dia 12 de novembro de 2015 no O Povo (O Povo Online, 2015b). Ou seja, a construção do potencialmente perigoso traz consigo a possibilidade de sua eliminação, dada a necessidade de gestão das virtualidades, daquilo que ele pode ainda não ter feito, mas possivelmente fará (Lemos, Scheinvar \& Nascimento, 2014).

O medo passa a fundamentar determinadas políticas de ordem e ações violentas do Estado em nome da segurança, da paz e da proteção. A utilização do medo e da insegurança como ferramentas de governamentalização se faz possível a partir de uma produção do "viver acuado" (Passos \& Carvalho, 2015). Ou 
seja, esse medo não emana de uma interioridade, mas sim de uma governamentalidade que o transforma em um operador político, implicando numa política de subjetivação que

têm contribuído para a projeção pública de uma verdadeira diabolização da "periferia", traduzida em espacialidade privilegiada de incertezas, medos e insegurança, a alimentar estigmatizações e segregações socioterritoriais que resvalam sobre seus moradores (Passos, \& Carvalho, 2015, p. 238).

A partir de episódios como a Chacina de Messejana, podemos problematizar também a presença massiva do Estado nas periferias sobretudo por meio da "habitual truculência das polícias brasileiras" (Kehl, 2015, p. 79). As abordagens policiais nos lembram que o Estado sempre esteve e está presente nas margens urbanas sobretudo pelo engendramento de práticas punitivas e de controle social, e não a partir de políticas que pudessem implementar o acesso a condições mínimas de usufruto de uma vida democrática. A título de ilustração, no estado do Ceará, segundo dados da própria Secretaria de Segurança Pública e Defesa Social (SSPDS), as mortes por intervenção policial em 2017 tiveram uma elevação de 74\% com relação aos anos de 2016 e 2015.

Um dos maiores efeitos da polícia e da política militarizadas é a reiteração da aludida produção do inimigo, que faz com que, em nome da proteção à vida dos tidos como "cidadãos", naturalize-se o extermínio dos tidos como "não cidadãos". Produções como a de Batista (2003) nos mostram como a lógica neoliberal pós-ditadura amplia desigualdades sociais e redimensiona quem são os inimigos internos, na medida em que este passa a ser cada vez mais personificado na figura do "traficante", progressivamente associada a um amplo espectro de populações pobres, especialmente jovens negros, vítimas do desamparo e do desemprego, cada vez mais recrutados a exercer funções subalternas na dinâmica do tráfico de drogas, na condição de vidas descartáveis.

A partir das relações entre violência, biopolítica e governamentalidade, dada a emergência das tecnologias de poder características do que Foucault (2008) cunhou de "dispositivos de segurança", é cabível a seguinte questão: o que há em comum entre as vítimas da chacina de messejana e a ampla parcela de jovens que morrem vítimas de homicídios em Fortaleza e em outros pontos do território brasileiro? Ambos evidenciam uma política de eliminação da figura do Homo Sacer discutida por Agamben (2009). A letalidade juvenil é uma das faces mais evidentes da transformação das margens urbanas em campos abertos onde vidas são "matáveis", expostas a violências simbólicas e concretas, e suas mortes não provocam comoção.

\section{Implicações da Psicologia na luta por democracia: o Vieses-UFC e a problematização dos homicídios de jovens}

De acordo com os aspectos debatidos nas seções anteriores, produzir uma vida não fascista implica reagrupar forças democráticas e de insurgência frente às composições tirânicas e às maquinarias da morte que produzem vidas "desimportantes", afrontando-as pela reflexão e pela ação (micro)política. Nesses termos, como sugerem os princípios aludidos por Foucault (1993), pensamento e intervenção política constituem domínios contíguos, relações, revezamentos.

Dessa maneira, encerraremos este artigo pautando possibilidades de implicação ético-política da Psicologia na luta (micro)política por processos de democratização real. Para tanto, apresentaremos caminhos de pesquisa e intervenção trilhados pelo Grupo de Pesquisas e Intervenções sobre Violências e Produção de Subjetividades (Vieses), ligado ao Departamento de Psicologia e ao Programa de Pós-Graduação em Psicologia da Universidade Federal do Ceará (UFC).

O Vieses/UFC foi criado em agosto de 2015, primeiramente como Grupo de Pesquisa cadastrado junto ao CNPq. Já naquele ano, ampliou seu escopo e se tornou também um Programa de Extensão, promovendo ações de médio e longo prazo que articulam pesquisa, extensão e ensino, com vistas à produção de intercessões entre a universidade e outros agentes sociais. Assim, suas atividades pretendem incidir a um só tempo na qualificação de processos formativos dentro e fora da Universidade e em práticas micropolíticas de produção de resistências e criações no cotidiano da cidade de Fortaleza em torno das problemáticas da violência e das tramas de exclusão social e inclusão social perversa, em suas diversas expressões e contextos, com destaque para suas implicações nos modos de subjetivação.

O Vieses/UFC pretende operar como dispositivo de problematização dos modos de subjetivação contemporâneos em suas conexões com: (1) expressões de violência, relações de poder, dominação que se 
inscrevem no cotidiano das práticas sociais; (2) políticas públicas, direitos humanos e práticas institucionais em campos diversos, tais como saúde, assistência social, justiça e educação; (3) práticas de captura e resistência no âmbito de movimentos sociais voltados ao enfrentamento das diversas expressões da violência; (4) micropolíticas de pesquisa e inter(in)venção em Psicologia em contextos de violência..

A criação do Vieses-UFC justificou-se pela pertinência de pôr em análise o dispositivo da violência, cartografando as linhas de saber-poder-subjetivação que o constituem. Temáticas ligadas à violência têm feito com que cada vez mais agentes "psi" sejam demandados em diversos planos institucionais, o que requer espaços acadêmicos de problematização da rede de saber-poder-subjetivação engendrada por essas práticas. Ademais, o Vieses-UFC encontra sua razão de existência na necessidade de problematizar o imaginário social que associa pobreza, risco, periculosidade e violência (Hillesheim, \& Cruz, 2008), em contraposição aos saberes e fazeres instituídos para operar o que Foucault chamou de "ortopedias sociais", em suas discussões genealógicas sobre as dinâmicas de exclusão-inclusão social na Modernidade e as práticas dirigidas aos considerados "anormais".

Doravante, daremos destaque às suas atividades de pesquisas e intervenções, a fim de trazermos contribuições concretas acerca das possíveis implicações ético-políticas no enfrentamento de modos fascistas de viver.

No tocante ao eixo de pesquisa, desde 2015 encontra-se em andamento a pesquisa guarda-chuva intitulada "Juventude e violência urbana: cartografia de modos de subjetivação na cidade de Fortaleza-CE”, que conta com participação de estudantes de graduação e pós-graduação, assim como de docentes da UFC e de outras instituições públicas de ensino superior. Contemplada pelo Edital $\mathrm{n}^{\circ}$ 01-2016 Universal do $\mathrm{CNPq}$, o objetivo geral da pesquisa tem sido cartografar modos de subjetivação agenciados por práticas sociais acerca do fenômeno da violência urbana envolvendo jovens em territórios da cidade de Fortaleza identificados pelos mais expressivos índices de homicídios. Para tanto, conta com uma frente quantitativa, que analisa bancos de dados sobre violência letal na capital cearense, e uma frente qualitativa, alinhada à perspectiva da pesquisa-intervenção, que se operacionaliza pela inserção em bairros de três regiões da cidade de Fortaleza com os mais eleva- dos índices de homicídios na juventude, utilizando a triangulação de estratégias metodológicas, tais como observação e conversas no cotidiano com jovens, seus familiares e trabalhadores sociais inseridos nos territórios; entrevistas semiestruturadas e grupos de discussão com esses atores sociais acerca da questão da violência urbana envolvendo jovens.

No que diz respeito à incidência técnico-política do Vieses-UFC em questões atinentes às políticas públicas locais, por meio dessa pesquisa, integrantes do Vieses-UFC têm colaborado, desde o final de 2015, com as atividades do Comitê Cearense pela Prevenção de Homicídios na Adolescência, iniciativa da Assembleia Legislativa do Estado do Ceará e do Unicef. O propósito deste comitê é investigar aspectos envolvidos no aumento dos homicídios desses segmentos no Estado e criar recomendações ao poder executivo local para o enfrentamento dessa problemática. Além disso, temos participado também da Comissão de Monitoramento do Sistema Socioeducativo Local do Fórum Permanente de Organizações Não Governamentais de Defesa dos Direitos da Criança e do Adolescente (Fórum DCA-Ceará) e iniciado parcerias com a Defensoria Pública do Estado do Ceará em relação ao acompanhamento de familiares e amigos de vítimas de violência letal.

Derivados da pesquisa acima aludida, foram gestados três projetos de extensão, apresentados brevemente a seguir.

- Re-Tratos da juventude: Seu objetivo geral é criar dispositivos de análise coletiva e intervenção micropolítica, de caráter transversal e intersetorial, em torno dos processos de subjetivação e dos direitos humanos de juventudes, em territórios da cidade de Fortaleza-CE. A execução do projeto se dá por meio da criação de dispositivos grupais, tais como oficinas e rodas de conversa, direcionados a profissionais de equipamentos sociais públicos da cidade de Fortaleza, a jovens que participam de tais equipamentos e a familiares de jovens vítimas de violência letal, a fim de produzir tratos das juventudes diversos à tutela, segregação, criminalização e aos silenciamentos os mais diversos.

- EntreTantos: conversações sobre violências contra jovens: Tal projeto possui uma dupla aposta, que é tecer redes de conversações no cotidiano da cidade entre universidade, 
movimentos sociais e coletivos juvenis voltadas à ampliação de problematizações acerca de violências contra jovens em Fortaleza, bem como produzir contrapontos ao recrudescimento de perspectivas moralizantes, individualizantes, eminentemente repressivas e de maximização do estado penal no tocante ao fenômeno da violência envolvendo juventudes inseridas nas margens urbanas, em especial. Metodologicamente, o projeto possui três eixos de ação, quais sejam: a) cartografia de coletivos juvenis e movimentos sociais ligados à atuação com juventudes, acompanhando suas formas de organização, mapeando suas micropolíticas de resistência à sujeição criminal de juventudes pobres e à combinação de práticas menoristas, proibicionistas e higienistas no cotidiano da cidade; b) rodas de conversações com coletivos e movimentos sociais sobre temas ligados à questão da violência contra jovens, a fim de ampliar as possibilidades de análise e intervenção micropolítica desses atores sociais nos espaços urbanos; C) Ciclos de Debate do Vieses/UFC, articulando integrantes da universidade e atores sociais da cidade, a fim de agenciar encontros em torno de experiências e análises acerca do enfrentamento de diversas expressões da violência contra segmentos juvenis em situação de exclusão social e,ou inclusão perversa.
- Histórias desmedidas: trajetórias juvenis e outros riscos: Seu título é inspirado no Documentário “Crônicas (Des)Medidas", média-metragem cujos roteiro e direção são da Profa. Dra. Alyne Alvarez Silva. O projeto possui dois propósitos principais: a) construir espaços de problematização com jovens a quem se atribui o cometimento de ato infracional e que cumprem medida socioeducativa de meio aberto em equipamentos da cidade de Fortaleza acerca de suas histórias e perspectivas de vida, por vezes silenciadas, invisibilizadas ou reduzidas ao signo da periculosidade, violência e anormalidade, com vistas à afirmação da multiplicidade de juventudes e à experimentação, nesta cartografia psicossocial, do riscar de novos territórios existenciais; b) fortalecer a incidência da Psicologia no âmbito do sistema socioeducativo local; nesse sentido, vem contribuindo com o monitoramento do sistema socioeducativo local realizado pelo Fórum DCA, denunciando práticas violações e violências nos contextos de internação, as precariedades e aprisionamentos simbólicos existentes na execução de medidas de meio aberto e tecendo, em conjunto com diversos integrantes da sociedade civil, recomendações técnicas ao poder público local; além disso, colaborou com o Conselho Regional de Psicologia - CRP 11 na atualização das referências técnicas para atuação dos psicólogos em medidas socioeducativas de meio fechado.

\section{Referências}

Agamben, G. (2004). Estado de exceção. São Paulo, SP: Boitempo.

Agamben, G. (2009). Homo Sacer: o poder soberano e a vida nua 1. Belo Horizonte, MG: Editora UFMG.

Barreira, C., \& Batista, E. (2011). Violência e conflito social. In C. Barreira, \& E. Barboza (Orgs.), Segurança e sociedade: treze lições (pp. 11-18). Campinas, SP: Pontes.

Barros, J. P. P., Acioly, L. F., \& Ribeiro, J. A. D. (2016). Re-Tratos da juventude na cidade de Fortaleza: direitos humanos e intervenções micropolíticas. Revista de Psicologia, 7(1), 115-128. Recuperado de http://www.periodicos. ufc.br/psicologiaufc/article/view/3677/2902

Batista, N. (1997) Introdução crítica ao direito penal brasileiro. Rio de Janeiro, RJ: Revan.

Batista, V. M. (2015). A juventude e a questão criminal no Brasil. In: Magalhães, J. L.Q., Salum, M. J. G., \& Oliveira, R. T. Por que somos contrários à redução da maioridade penal? Brasília, DF: Conselho Federal de Psicologia.

Batista, V. M. (2012). Adesão subjetiva à barbárie. In: Loic Wacquant e a questão penal no capitalismo neoliberal. Rio de Janeiro: Revan.

Batista, V. M. (2003). Difíceis ganhos fáceis: drogas e juventude pobre no Rio de Janeiro. Rio de Janeiro, RJ: Revan.

Bicalho, P. P., Barbosa, R. B., \& Meza, A. P. S. (2015). Juventude no fogo cruzado: o governo da vida e das políticas dicotômicas de segurança. In A. Scisleski, \&N. Guareschi. (Org.), Juventudes, marginalidade social e direitos humanos: da psicologia às políticas públicas (pp. 205-219). Porto Alegre, RS: EdiPUCRS. 
Cerqueira, D., \& Coelho, D. S. C. (2015). Redução da idade de imputabilidade penal, educação e criminalidade (Nota técnica, n. 15). Brasília, DF: IPEA.

Cerqueira, D., Ferreira, H., Lima, R. S., Bueno, S., Hanashiro, O., Batista, F., \& Nicolato, P. (2016). Atlas da violência 2016 (Nota técnica, n. 17). Brasília, DF: IPEA.

Cerqueira, D., Lima, R. S., Bueno, S., Valencia, L. I., Hanashiro, O., Machado, P. H. G., \& Lima, A. S. (2017). Atlas da violência 2017. Brasília, DF: IPEA.

Coimbra, C.; Scheinvar, E. (2012). Subjetividades punitivo-penais. In:V. M. Batista (Org.), Loic Wacquant e a questão penal no capitalismo neoliberal (pp. 59-68). Rio de Janeiro, RJ: Revan.

Coimbra, C. (2001). Operação Rio: o mito das classes perigosas. Rio de Janeiro, RJ: Intertexto.

Coimbra, C. M. B., Lobo, L. F., \& Nascimento, M. L. (2008). Por uma invenção ética para os direitos humanos. Psicologia Clínica, 20(2), 89-102. https://doi.org/10.1590/S0103-56652008000200007

Coimbra, C. M. B., \& Nascimento, M. L. (2003) Jovens pobres: o mito da periculosidade. In P. C. P. Fraga, \& J. A. S. Iulianelli (Orgs.), Jovens em tempo real. Rio de Janeiro, RJ: DP\&A editora.

Deleuze, G., \& Guatarri, F. (1991). O anti-Édipo: capitalismo e esquizofrenia. São Paulo, SP: Editora 34.

Fortaleza (2016). Secretaria Municipal de Saúde. Homicídios de crianças e adolescentes de 10 a 19 anos em Fortaleza: análise epidemiológica e espacial 2000-2016. Fortaleza, CE, o autor.

Fórum Brasileiro de Segurança Pública. (2015). Anuário Brasileiro de Segurança Pública 2015. São Paulo, SP: Autor.

Fórum Brasileiro de Segurança Pública. (2016). Anuário Brasileiro de Segurança Pública 2016. São Paulo, SP: Autor.

Foucault, M. (1993). Anti-édipo: introdução à vida não fascista. Cadernos de Subjetividade, 1(1), 197-200. Recuperado de http://letraefilosofia.com.br/wp-content/uploads/2015/03/foucault-prefacio-a-vida-nao-facista.pdf?x70961

Foucault, M. (1994). Dits et écrits (2a ed.). Paris: Gallimard.

Foucault, M. (2005). Em defesa da sociedade. São Paulo, SP: Martins Fontes.

Foucault, M. (2008). Segurança, território, população. São Paulo, SP: Martins Fontes.

Fraga, P. C. P. (2004). Política, isolamento e solidão: práticas sociais na produção da violência contra jovens. In M. A. Sales, M. C. Matos, \& M. C. Leal, Política social, família e juventude: uma questão de direitos (pp. 81-103). Rio de Janeiro, RJ: Cortez.

Franco, I. (2017, 6 de janeiro). Sobre chacina, secretário de Temer diz que "tinha era que matar mais". O Globo. Recuperado de http://blogs.oglobo.globo.com/panorama-politico/post/sobre-chacina-secretario-de-temer-diz-que-tinha-era-que-matar-mais.html

Guattari, F. (1987). Revolução molecular: pulsões políticas do desejo (3a ed.). São Paulo, SP: Brasiliense.

Guattari, F., \& Rolnik, S. (2007). Micropolítica: cartografias do desejo. Petrópolis, RJ: Vozes.

Hillesheim, B., \& Cruz, L. R. (2008). Risco, vulnerabilidade e infância: algumas aproximações. Psicologia \& Sociedade, 20 (2), 192-199. https:// doi.org/10.1590/S0102-71822008000200006

Kehl, M. R. (2015). Duas chacinas em São Paulo: a mesma polícia, o mesmo governo. In B. Kucinski, C. I. L. Dunker, I. Pereira, F. Mena, G. Mingardi, \& J. Wyllys et al. Bala perdida: a violência policial no Brasil e os desafios para sua superação (pp. 75-81). São Paulo, SP: Boitempo.

Lemos, F. C. S., Scheinvar, E., \& Nascimento, M. L (2014). Uma análise do acontecimento "crianças e jovens em risco". Psicologia \& Sociedade, 26(1), 158-164. https://doi.org/10.1590/S0102-71822014000100017

Martins, J. S (2015). Linchamentos: a justiça popular no Brasil. São Paulo, SP: Contexto.

Melo, D. L. B., \& Cano, I. (2017) I. Índice de homicídios na adolescência: IHA 2014. Rio de Janeiro, RJ: Observatório de Favelas.

Mingardi, G. (2015) Apresentação. In B. Kucinski, C. I. L. Dunker, I. Pereira, F. Mena, G. Mingardi, J. Wyllys et al. Bala perdida: a violência policial no Brasil e os desafios para sua superação (pp. 13-17). São Paulo, SP: Boitempo. 
Narlla, H. (2015). Tribuna do Ceará. Nenhuma das vítimas de chacina da Messejana tinha antecedentes criminais graves. Recuperado em 29 junho, 2017, de http://tribunadoceara.uol.com.br/noticias/segurancapublica/ nenhuma-das-vitimas-de-chacina-da-messejana-teria-antecedentes-criminais-graves /

O Povo Online. (2015b, 12 de novembro). Secretaria divulga lista dos 11 mortos em chacinas na Grande Messejana. Recuperado de http://www20.opovo.com.br/app/fortaleza/2015/11/12/noticiafortaleza,3532865/secretaria-divulga-lista-dos-11-mortos-em-chacinas-na-grande-messejana.shtml

O Povo Online. (2015a, 12 de novembro). SSPDS monta força-tarefa para investigar chacinas e homicídios. Recuperado de http://www20.opovo.com.br/app/fortaleza/2015/11/12/noticiafortaleza,3532691/sspds-monta-forca-tarefa-para-investigar-chacinas-e-homicidios.shtml

Paiva, L. F. S. (2015). Mortes na periferia: considerações sobre a chacina de 12 de novembro em Fortaleza. O Público e o Privado, (26), 269-281. Recuperado de http://seer.uece.br/?journal=opublicoeoprivado\&page=article\&op=view\&path\%5B\%5D=1414\&path\%5B\%5D=1345

Paiva, L. F. S., \& Freitas, G. J. (2015). Ecos da violência nas margens de uma sociedade democrática: o caso da periferia de Fortaleza. Sociedade e Cultura, 18(2), 115-128. https://doi.org/10.5216/sec.v18i2.42379

Passos, L. M., \& Carvalho, A. M. P. (2015). Medo e Insegurança nas margens urbanas: uma interpretação do \viver acuado $₫$ em território estigmatizados do Grande Bom Jardim. UECE. Fortaleza: O público e o privado, 26(1), 233259. http://www.seer.uece.br/?journal=opublicoeoprivado\&page=article\&op=view\&path\%5B\%5D=1371

Santos, J. V. T. (2011) A expressão da violência e a construção da paz. In C. Barreira, C., \& E. Batista (Orgs.), Segurança e Sociedade: treze lições (7-10). Campinas, SP: Pontes.

Souza, T. P. (2014). O nascimento da biopolítica das drogas e a arte neoliberal de governar. Fractal: Revista de Psicologia, 26(3), 979-998. https://doi.org/10.1590/1984-0292/1246

Zaccone, O. E. F. (2015). Indignos de vida: a forma jurídica da política de extermínio de inimigos na cidade do Rio de Janeiro. Rio de Janeiro, RJ: Revan.

Waiselfisz, J. J. (2016). Mapa da Violência 2016: homicídios por armas de fogo no Brasil. Brasília, DF: FLACSO.

Waiselfisz, J. J. (2015). Violência letal contra as crianças e adolescentes do Brasil. Brasília, DF: Flacso.

João Paulo Pereira Barros

Psicólogo, mestre em Psicologia e doutor em Educação Brasileira pela Universidade Federal do Ceará (UFC), Fortaleza - CE. Brasil. Especialista em Saúde Mental pela Universidade Estadual do Ceará (UECE), Fortaleza - CE. Brasil.

E-mail: jppbarros@yahoo.com.br

Luis Fernando de Souza Benício

Psicólogo pela Faculdade DeVry Fanor, mestrando em Psicologia pela Universidade Federal do Ceará (UFC), Fortaleza - CE. Pesquisador-Bolsista da Coordenação de Aperfeiçoamento de Pessoal de Nível Superior (CAPES).

E-mail: luisf.benicio@gmail.com

Dagualberto Barboza da Silva

Graduando em Psicologia pela Universidade Federal do Ceará (UFC), Fortaleza - CE. Brasil. Bolsista de Iniciação Científica - PIBIC/CNPq.

E-mail: dalgobarboza92@gmail.com

\section{Camila dos Santos Leonardo}

Graduanda em Psicologia pela Universidade Federal do Ceará (UFC), Fortaleza - CE. Brasil. Bolsista de Iniciação Científica - PIBIC/CNPq.

E-mail: myllaleonardo32@gmail.com 


\section{Frida Tainá Popp Torres}

Jornalista pela Universidade Federal do Ceará (UFC), Fortaleza - CE. Brasil

E-mail: poppfrida@gmail.com

Endereço para envio de correspondência:

Avenida da Universidade, 2762, Benfica - CEP: 60.020-180, Fortaleza, Ceará - Brasil.

Recebido $21 / 07 / 2017$

Aprovado 02/10/2017

Received $07 / 21 / 2017$

Approved 10/02/2017

Recebido 21/07/2017

Aceptado 02/10/2017

Como citar: Barros, J. P. P., Benício, L. F. S., Silva, D. B., Leonardo, C. S., Torres, F. J. P. (2017). Homicídios juvenis e os desafios à democracia brasileira: implicações ético-políticas da Psicologia. Psicologia: Ciência e Profissão, 37(4), 1051-1065. https://doi.org/10.1590/1982-3703002892017

How to cite: Barros, J. P. P., Benício, L. F. S., Silva, D. B., Leonardo, C. S., Torres, F. J. P. (2017). Juvenile homicides and the challenges to brazilian democracy: ethical-political implications of Psychology. Psicologia: Ciência e Profissão, 37(4), 1051-1065. https://doi.org/10.1590/1982-3703002892017

Cómo citar: Barros, J. P. P., Benício, L. F. S., Silva, D. B., Leonardo, C. S., Torres, F. J. P. (2017). Homicidios Juveniles y los desafíos a la democracia brasileña: implicaciones ético-políticas de la Psicología. Psicologia: Ciência e Profissão, 37(4), 1051-1065. https://doi.org/10.1590/1982-3703002892017 